\title{
Review of Available Products of Leaf Area Index and Their Suitability over the Formerly Soviet Central Asia
}

\author{
M. W. Kappas and P. A. Propastin \\ Department of Geography, Georg-August University of Göttingen, Goldschmidtstraße 5, 37077 Göttingen, Germany \\ Correspondence should be addressed to M. W. Kappas, mkappas@gwdg.de
}

Received 7 June 2011; Revised 16 November 2011; Accepted 19 December 2011

Academic Editor: Tuan Guo

Copyright (c) 2012 M. W. Kappas and P. A. Propastin. This is an open access article distributed under the Creative Commons Attribution License, which permits unrestricted use, distribution, and reproduction in any medium, provided the original work is properly cited.

Leaf area index (LAI) is a key biophysical variable for environmental process modelling. Remotely sensed data have become the primary source for estimation of LAI at the scales from local to global. A summary of existing LAI data sets and a discussion of their appropriateness for the formerly Soviet Central Asia, especially Kazakhstan, which is known for its huge grassland area (about 2 million $\mathrm{km}^{2}$ ), are valuable for environmental modelling in this region. The paper gives a brief review of existing global LAI products, such as AVHRR LAI, MODIS LAI, and SPOT-VEGETATION LAI, and shows that validation of these products in Kazakhstan as well as in other countries of the formerly Soviet Central Asia has not been carried out yet. Apart from the global LAI products, there are just a few data sets retrieved by remote sensing methods at subregional and regional scales in Kazakhstan. More research activities are needed to focus on the validation of the available global LAI products over the formerly Soviet Central Asia and developing new LAI data sets suitable for application in environmental modelling at different scales in this region.

\section{Introduction}

Usually, the Leaf area index (LAI) is defined as one half the total leaf area per unit ground surface area projected on the local horizontal area (e.g., [1]). The LAI is well adapted for flat leaves as, for example, grass, crops, and deciduous forests. In coniferous woodland, shoot is considered as the foliage element, and the assembly of needles (e.g., angle, shape) should be taken into account (e.g., as clumping index). In deciduous forests the measurements need to be corrected for clumping index as well, but at scales larger than that of a shoot.

The LAI is a significant ecological attribute that controls vegetation photosynthetic activity. As such, LAI plays an essential role in climate, weather, and ecological studies. In the realm of possible climate change and its influence on landscape's future $\mathrm{CO}_{2}$ sequestration potential, more precise knowledge about the theoretical production ecology of the various world biomes (wetlands, woodlands, shrublands, or grasslands) is essential. LAI is widely used as input variable for land surface modelling of biosphere processes, and especially for predictions of photosynthetic primary production $[2,3]$.

The LAI belongs to the biophysical variables which are useful to the development of knowledge in climate and environmental sciences, to understand the climatic system and ecophysiological processes. The biophysical parameters are also indispensable as input to environmental services that use these data, at the same time as other data types (in situ, agrometeorological models, etc.) to produce environment monitoring indicators (water quality, drought or famine risks, desertification, deforestation/reforestation, etc.).

Especially for the formerly Soviet Central Asia with its huge grassland areas, the allocation of biophysical parameters like LAI is more and more required. Despite of climate aridity, the grassland ecosystems of Central Asia represent a gigantic reservoir of carbon and play a very considerable role in the global change $[4,5]$. Both the climatic conditions and physiographic patterns vary significantly within this region presenting a broad spectrum of various landscapes within 
the grassland biome of Central Asia. Grasslands of Central Asia distinguish considerably from grasslands in other regions, making difficult adaptation of any global analysis approach to the Central Asian region. The history of land use change occurred in Central Asia (especially in Kazakhstan) in the wake of political change (the collapse of the Soviet Union in 1991). This dramatic change in land use is unique in its kind in the whole 20th century, making the difference of the Central Asian grassland to other regions more significant. This historical development is also an excellent opportunity to improve the understanding of the linkages between carbon balance, climate, and land use change in dryland ecosystems with the help of biophysical parameters which reveal knowledge about the landscape's dynamic.

Within this scope, the presented paper

(i) gives a brief review of the available LAI products for Central Asia and especially Kazakhstan,

(ii) outlines their suitability for ecological modelling in grasslands of Central Asia, and

(iii) gives an outlook with respect to future research needs.

\section{LAI Estimation from Remote Sensing and Ground Truth Data}

Between LAI and light interception, an inverse exponential relation has been found, which is linearly proportional to the primary production rate. Gross primary production (GPP) is the rate at which producers inside an ecosystem capture and store a given amount of chemical energy as biomass in a given time span. Some fraction of this fixed energy is used by primary producers for cellular respiration and maintenance of existing tissues (i.e., "growth respiration" and "maintenance respiration," as discussed by [6]). The remaining fixed energy in form of plant mass (i.e., product of photosynthesis) is referred to as net primary production $(\mathrm{NPP}=\mathrm{GPP}-$ respiration [by plants] $)$.

NPP is the rate at which all the plants in an ecosystem produce net useful chemical energy. It is equal to the difference between the rate at which the plants in an ecosystem produce useful chemical energy (GPP) and the rate at which they use some of that energy during respiration. Some NPP goes toward growth and reproduction of primary producers, while some NPP is consumed by herbivores. Both gross and net primary production is measured in units of mass/ area/time. In terrestrial ecosystems, the mass of carbon per unit area per year $\left(\mathrm{g} \mathrm{C} / \mathrm{m}^{2} / \mathrm{yr}\right)$ is most often used as the measurement unit (e.g., for assessment of $\mathrm{CO}_{2}$ sequestration). LAI measurements are a helpful tool to predict photosynthetic primary production (e.g., GPP, NPP).

LAI estimation from remote sensing data is done by the analysis of multispectral and multidirectional surface reflectance signatures of vegetation that performs photosynthesis [7]. In general two basic approaches are used to get LAI from surface reflectance.

(1) Empirical or semiempirical relationships between LAI and vegetation indices (i.e., NDVI, combination of surface reflectances) are used [7]. The vegetation index (VI) is designed to maximize sensitivity to the vegetation characteristics while minimizing disturbing factors such atmospheric noise, soil background, or view-illumination geometry. These relationships between LAI and VI's are specifically calibrated for distinct vegetation types using either coexistent in situ LAI and reflectance measurements or simulations from canopy radiation models $[8,9]$.

(2) Inversion of a radiative transfer model which models surface reflectance from canopy structural characteristics (including LAI), soil and leaf optical properties, and view-illumination geometry is used $[7,8,10]$. lookup tables (LUT, [11]) and neural networks [10, 12] are the main inversion techniques deriving LAI from radiative transfer models. The expected range of the model parameters is either set up for each vegetation type (e.g., MODIS algorithm) or globally modelled (e.g., CYCLOPES algorithm).

Ancillary to the above-mentioned basic approaches, preor postprocessing steps are used to remove residual atmospheric, cloud contamination, and view-illumination effects inside the satellite data. In many cases compositing techniques are calculated to filter or smooth reflectance (e.g., CYCLOPES algorithm, MODIS algorithm, GLOBCARBON, or CCRS algorithms) [7]. All techniques try to identify noisy data in the LAI seasonal time series in order to replace them by smoothed LAI values [13-16]. Tan et al. [16] for instance built up phenology metrics based on temporally smoothed and spatially gap-filled MODIS indices as LAI, Normalized Difference Vegetation Index (NDVI), and Enhanced Vegetation Index (EVI) over North America. The spatial coverage of this data set is more complete than other phenology products. This originated from the quality of the smoothed and gap-filled MODIS data that was produced using an enhanced version of the TIMESAT algorithm [15].

Together with other remote sensing products as land use/ land cover (LULC) maps, the LAI is used as input data for NPP models or biomass models. Land cover is an input of LAI algorithms, and land cover maps are widely used to parameterize the biophysical properties of plant canopies in models. Mostly, supervised classification algorithms are used to generate land cover maps that characterize the vegetation types required for LAI and Fraction of Absorbed Photosynthetically Active Radiation (fAPAR) retrievals from remote sensing data such as MODIS. Inside this process, the sensitivity of remote sensing-based retrievals of LAI and FAPAR to land cover information is used to parameterize vegetation canopy radiative transfer models. Figure 1 shows the land-cover distribution over Kazakhstan and middle Asia based on the MODIS landcover map.

Added to Figure 1 is Table 1 with concrete data about the total numbers of pixels for each land-cover type.

This information in form of land use/land cover data and LAI data allow the assessment of ground pixels in terms of net primary productivity. 


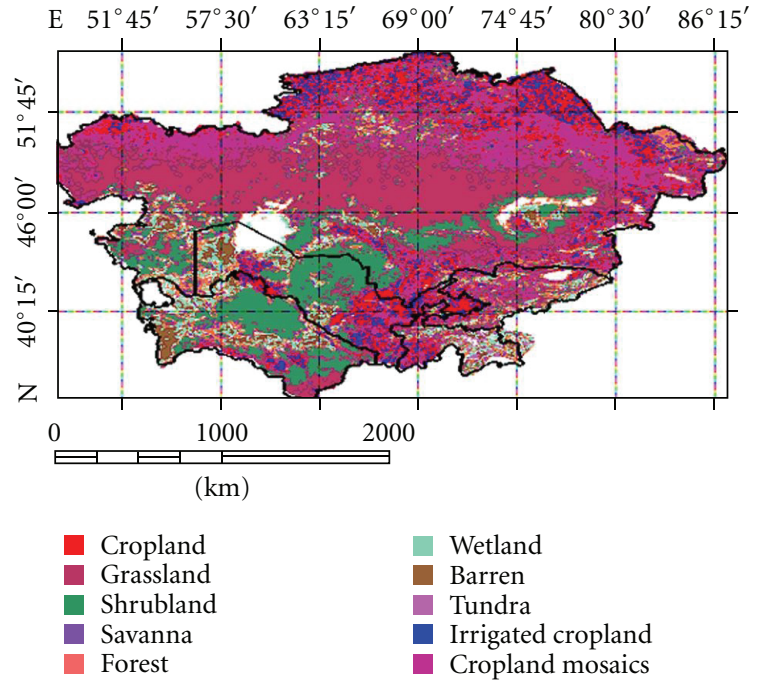

FIgure 1: Land-cover distribution over Kazakhstan and Middle Asia based on the MODIS land-cover map (source: Propastin et al. [17]).

TABLE 1: The total number of pixels within each land-cover type, its area and percentage in Central Asia based on the 2001 MODIS land cover map (source: Propastin et al. [17]).

\begin{tabular}{lccc}
\hline Land cover type & $\begin{array}{c}\text { Number of } \\
\text { pixels }\end{array}$ & $\begin{array}{c}\text { Area in } \\
\text { mill } \cdot \mathrm{km}^{2}\end{array}$ & $\begin{array}{c}\text { Percentage, } \\
\%\end{array}$ \\
\hline Cropland & 9008 & 0.609 & $10,92 \%$ \\
Irrigated cropland & 4163 & 0.266 & 4,79 \\
Cropland mosaic & 18535 & 1.186 & 21,67 \\
Grassland & 26951 & 1.725 & 31,32 \\
Shrubland & 13186 & 0.844 & 15,2 \\
Savanna & 2077 & 0.133 & 2,3 \\
Wetland & 3135 & 0.201 & 3,61 \\
Forest & 6616 & 0.423 & 7,59 \\
Tundra & 332 & 0.021 & 0,38 \\
BSV* & 2771 & 0.177 & 3,13 \\
\hline Total & 86774 & 5.578 & 100 \\
\hline
\end{tabular}

$\mathrm{BSV}^{*}$ : barren or sparsely vegetated.

The assessment of the pixel-based primary productivity can be used to improve estimates of the mentioned parameters on a continental scale in order to increase the accuracy of the flux predictions by providing timely judgements of the NPP. The knowledge about how vegetation changes over time and space is revealed by the knowledge of how reflected solar radiation is modified by the vegetation. In order to derive this knowledge, sensors that acquire information in the visible (VIS) and near-infrared (NIR) parts of the spectrum are analysed.

Most of the available remote sensing data sources during the past years have been satellite sensors with a low number of spectral bands in the visible and NIR wavelengths (e.g., AVHRR, Landsat). The needed plant parameters like LAI or fraction of absorbed photosynthetic active radiation (fAPAR) can only be roughly estimated. fAPAR is the fraction of photosynthetic active radiation $(400-700 \mathrm{~nm})$ absorbed by vegetation. While fAPAR is a key variable in the assessment of vegetation productivity and yield estimates, the LAI delivers valuable input more to climate and hydrologic modeling. Whereas fAPAR shows a positive linear relationship with increasing NDVI, LAI is nonlinearly related to NDVI, saturating at LAIs of 3-6, depending on the vegetation type [18]. In order to estimate LAI and fAPAR from remotely sensed data, canopy structural types must be defined as those which exhibit different NDVI/LAI or fAPAR relations from one another. Therefore, many classification schemes, which are based on ecological, botanical, or functional metrics, are not necessarily suitable for LAI and fAPAR retrieval. The utility of this relationship depends on the sensitivity of these variables to canopy characteristics [18]. The general relationships between VI such as NDVI and fAPAR were found to be linear. Nonlinear models gave a better fit for the VI/LAI relationship. In general the relation between fAPAR and NDVI is stronger than between LAI and NDVI. In situ measured fAPAR and NDVI normally show a strong linear relationship, suggesting that covariance between fAPAR and NDVI is insensitive to variations in leaf angle distribution (LAD) and vegetative heterogeneity $[18,19]$. A strong linear relation also exists between MODIS FAPAR and NDVI but with weaker regression coefficients than the in situ relationship because of MODIS tendency to overestimate fAPAR (around 8 to 20\%). The fAPAR/NDVI relations are reported not to apply on a global scale but are only valid for similar sun-sensor view geometry and soil colour [18].

All algorithms to derive these estimations about LAI or fAPAR are empirical and are based on a common relationship between the recorded signal and the respective plant parameter [19]. This oversimplification often leads to low accuracies in estimating these parameters and at last of GPP and NPP.

Estimations of fAPAR relying only on this type of simple relationship cannot differentiate between the absorption by photosynthetically active plant elements and the absorption by other plant stuff and soil. This is the main problem of the older sensors like AVHRR which on the other hand delivers the longest time series of observations on earth. Sensors of a newer generation like MODIS (launched in 1999) and MERIS (launched in 2002) open up new vistas. These new generation sensors and future advanced sensor developments (e.g., modified MERIS on SENTINEL-3, EnMap, NPOES) have more spectral channels at large and in the VIS and NIR domain in particular. Besides better spatial resolution, a better radiometric accuracy is available with these sensors. With the use of the newer sensors and in due consideration of different observation geometries during consecutive overpasses, it is possible to implement different techniques to invert models tracing the radiation transfer in vegetation. These models can be divided into coupled leaf and canopy radiation transfer models (e.g., PROSPECT and SAIL models, as discussed by Jacquemoud et al. [20]) or into a simple canopy component as the model inversion scheme mentioned above [21]. The well-known PROSPECT leaf optical properties model and SAIL canopy bidirectional reflectance model, also called PROSAIL in combination, have been used 


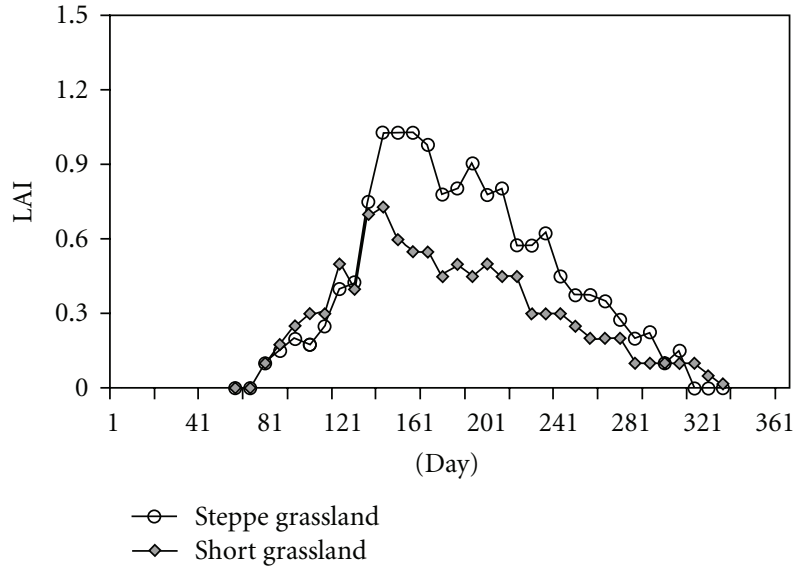

(a)

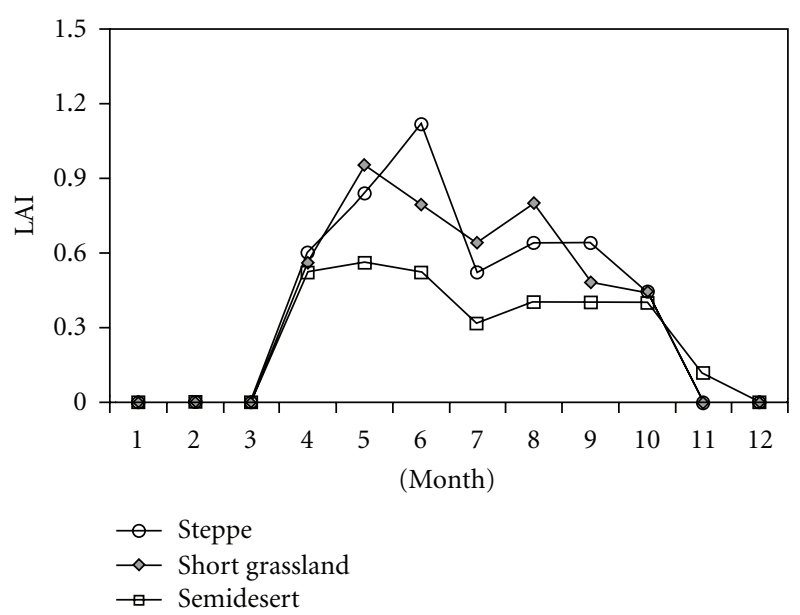

(b)

FIGURE 2: Typical time series of LAI over different grassland types of Kazakhstan derived from 8-day MODIS LAI product (a) and monthly AVHRR LAI product (b).

for about eighteen years to study plant canopy spectral and directional reflectance. PROSAIL has also been used to develop new methods for retrieval of vegetation biophysical properties. It combines the spectral variation of canopy reflectance, which is mainly related to leaf biochemical contents, with its directional variation, which is primarily related to canopy architecture and soil/vegetation contrast. This combination is important for the estimation of canopy biophysical/structural variables for applications in agriculture or ecology, at different scales (for review see [22]).

In order to perform an operational inversion of huge mounds of data, often lookup tables (LUTs) or neural networks techniques are applied. Plant parameters derived by the inversion of radiation transfer models offer a better and more precise characterisation of the vegetation properties. During the last years, models have been designed which are able to generate parameters such as leaf angle distribution (LAD), leaf area index (LAI), chlorophyll content, or canopy height $[11,11,23,24]$.

Handling this information inside radiation transfer models, fAPAR can be calculated with higher accuracy than with the simple functional relationship mentioned above. The LAI is hence a very important factor for the quantitative characterisation of canopies and the phenology of plants. Phenology, which is the plants developing during the growth period specific to the region where they grow, can be traced by LAI. This seasonal developing of the plants can be quantified as a time series of LAI which is a very important application to compare it with other environmental parameters (e.g., precipitation, temperature, soil organic matter) for ecological modelling.

In agriculture, phenology starts typically after sowing with an LAI near 0 (bare soil). The LAI increases during the growth period to a maximum value that is crop specific (e.g., 5 for maize).

Plant production models exist in varying levels of scope (physiological, individual plant, crop, geographical region, global) and of generality. The model can be crop specific or be more generally applicable. The crop growth model SUCROS (open source) has been developed during more than 20 years and is based on earlier crop models. The IRRI (International Rice Research Institute) and Wageningen University more recently developed the rice growth model ORYZA2000 (open source). The United States Department of Agriculture (USDA) has sponsored a number of applicable crop growth models for various major crops, such as cotton, soy bean, wheat, and rice. Other widely-used models are the precursor of SUCROS (SWATR), CERES, and several incarnations of PLANTGRO, SUBSTOR, the FAO-sponsored CROPWAT, AGWATER and the erosion-specific model EPIC.

Today, the LAI is frequently used for ecological modelling of biomass and the characterization of landscape dynamics. Most models need the LAI as input parameter or as surrogate to derive other plant parameters. For this reason long time series of LAI (many years) are needed for change detection. In Figure 2 typical time series of the LAI for a steppe area in Kazakhstan are shown.

2.1. Typical Values of Ground-Based LAI. The LAI can be explicitly measured in situ using a variety of techniques including destructive sampling, allometry, and optical observation methods (hemispherical photography, see $[1,23]$ ). The disadvantages of these techniques are that they are both geographically limited and time and costconsuming. Table 2 summarizes typical values of grassland LAI measured in different world regions. A benchmark of typical values and ranges of LAI for variety of biomes is given by Scurlock et al. [25]. In general, the LAI values reported for Central Asia (Kazakhstan) go well with the range of LAI values reported by [25] for corresponding biomes (as discussed by Propastin and Kappas [26]). They are also consistent with ground-measured LAI in grassland/shrubland of the western Sudano-Sahelian zone in Senegal [15], desert/shrubland in 
TABLE 2: Some of previous ground-based estimates of leaf area index in arid and semiarid zones.

\begin{tabular}{|c|c|c|c|}
\hline Country/region & Biome & LAI & Reference \\
\hline USA/Arizona & Desert/shrubland & $0.93 \pm 0.45$ & Whittaker and Niering [27] \\
\hline \multirow{2}{*}{ USA/New Mexico } & Grassland & $0.75 \pm 0.1$ & \multirow[t]{2}{*}{ Asner et al. [29] } \\
\hline & Shrubland & $1.58 \pm 0.3$ & \\
\hline Senegal/Sahel & Grassland & $0.15-2.5$ & Fensholt et al. [19] \\
\hline \multirow{3}{*}{ Australia } & Shrubland & $0.36 \pm 0.07$ & \multirow[t]{3}{*}{ Hill et al. [30] } \\
\hline & Grassland & $0.50 \pm 0.2$ & \\
\hline & Woodland & $1.89 \pm 0.64$ & \\
\hline \multirow{2}{*}{ Kazakhstan } & Grassland & $0.22-0.90$ & \multirow[t]{2}{*}{ Propastin and Kappas [26] } \\
\hline & Shrubland & $0.10-0.70$ & \\
\hline \multirow{3}{*}{ Worldwide } & Grassland & $0.29-5.47$ & \multirow[t]{3}{*}{ Scurlock et al. [25] } \\
\hline & Shrubland & $0.4-4.5$ & \\
\hline & Cropland & $0.2-8.7$ & \\
\hline
\end{tabular}

Arizona [27], and the northern Chihuahuan Desert in New Mexico, USA [28]. The intercomparison with other studies in grasslands gives us an indication for the possible range of LAI values of the grassland biome in Kazakhstan.

2.2. Estimation from Remote Sensing Data. Remote sensing provides the most feasible platform for spatially and temporally continuous observations of biophysical parameters at the scales from local to global [28, 31-34].

The impossibility to differentiate between the absorption by photosynthetically active plant elements and the absorption by other plant stuff and soil is the main problem of the older sensors like AVHRR. Sensors of a newer generation like MODIS and MERIS open up new views on this problem [20] or into a simple canopy component as the model inversion scheme mentioned above [21]. The PROSAIL model has also been used to develop new methods for retrieval of vegetation biophysical properties. It combines the spectral variation of canopy reflectance, which is mainly related to leaf biochemical contents, with its directional variation, which is primarily related to canopy architecture and soil/vegetation contrast $[29,35]$. This combination is important for the estimation of canopy biophysical/structural variables for applications in agriculture or ecology, at different scales (for review see [22]).

The LAI is hence a very important factor for the quantitative characterisation of canopies and the phenology of plants. Phenology can be traced by LAI. This seasonal developing of the plants can be quantified as a time series of LAI which is a very important application to compare it with other environmental parameters (e.g., precipitation, temperature, soil organic matter) for ecological modelling. In grassland, phenology starts typically with a value of LAI near 0 (bare soil). The LAI increases during the growth period to a maximum value that is cover specific (e.g., 1.0-1.2 for steppe grassland). In Figure 2 typical time series of the LAI for two major grassland types in Kazakhstan are shown, and in Figure 3 typical time series of the LAI derived from MODIS, Spot VGT, and AVHRR products for broadleaved forests over Kazakhstan are compared. In Figure 4 a spatial comparison

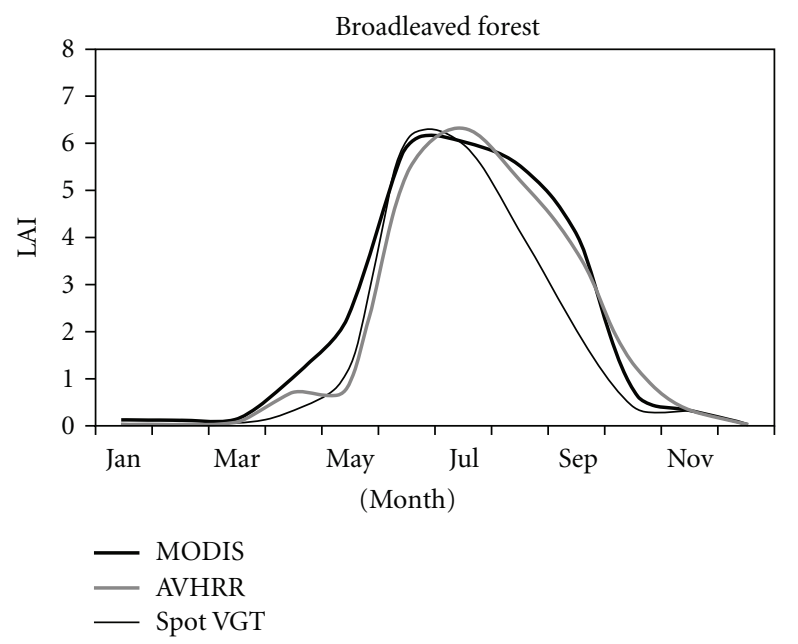

FIgure 3: Typical time series of LAI over broadleaf forests of Kazakhstan derived from monthly MODIS, Spot VGT, and AVHRR LAI product in 2002.

between Spot VGT and MODIS LAI to AVHRR LAI is shown, where LAI values below 1.8 have a higher correspondence.

\section{Available Satellite-Based LAI Data Sets for Grassland of Kazakhstan}

In the next chapters LAI data sets delivered by different remote sensing sensors will be specified. Global LAI data sets are generally produced using various approaches and algorithms applied to many sensors data in the frame of specialized projects: CYCLOPES, GEOLAND, VGT4AFRICA, POLDER, AMMA, and others. In general, for global and regional LAI products, we find three main sensors as data providers for LAI derivation over Kazakhstan: AVHRR, SPOT VEGETATION, and MODIS. The described global LAI products are available on an operational basis and are restricted to a spatial resolution not higher than $1000 \mathrm{~m} \times$ $1000 \mathrm{~m}$. The LAI products from higher resolution sensors 


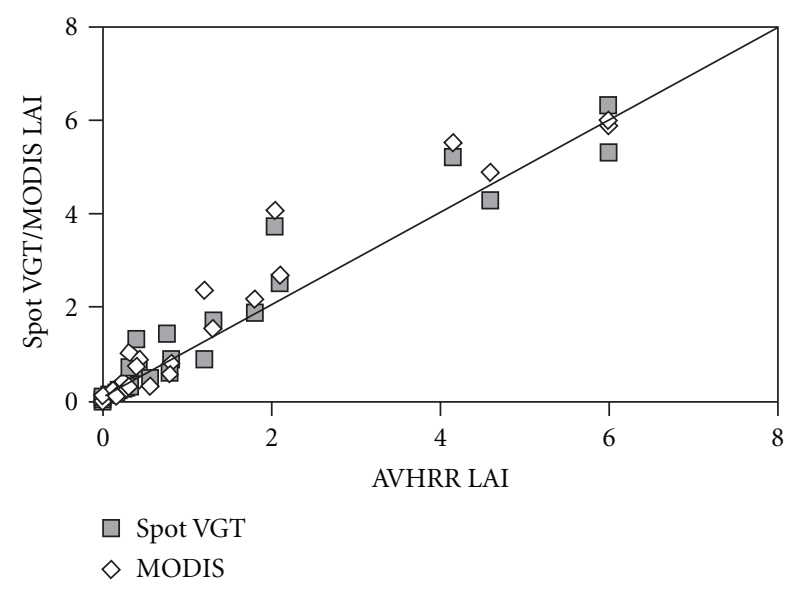

FIgURE 4: Spatial comparison of Spot VGT/MODIS LAI to AVHRR LAI cross over all land cover classes.

exist only on a local scale and only for short time periods (sometimes only for one over flight).

\subsection{Global LAI Products}

3.1.1. LAI Derived from AVHRR. LAI time series from AVHRR (Advanced Very High Resolution Radiometer) offer the longest coherent time series on the world. Boston University derived a global LAI data set from AVHRR data. The spatial resolution is available in three products: $8 \mathrm{~km}, 16 \mathrm{~km}$, and $0.5^{\circ}$ resolution. The $16 \mathrm{~km}$ and $0.5^{\circ}$ resolution LAI time series are available as monthly composites from July 1981 until May 2001, while the new $8 \mathrm{~km}$ AVHRR LAI product covers the period from July 1981 to September 2006. These products were produced from an improved version of the AVHRR Pathfinder Land NDVI Data set (source: Global Monitoring and Modelling Group (GIMMS), see [36]) using LAI versus NDVI relations build up by a radiative transfer model from Myneni $[8,37]$. The LAI is produced using a land cover map with 9 classes: water, nonearth, nonvegetated land, grass, shrub, broadleaf crops, savanna, broadleaf deciduous trees and needle leaf tree. Validation of the AVHRR LAI data set revealed good suitability of this product for climate simulations (see [38]).

The LAI products are stored as flat binary files (unsigned integer, 0-254). The $16 \mathrm{~km}$ LAI product is presented in Goode's projection with 2492 columns and 1084 rows. The $0.5^{\circ} \mathrm{LAI}$ product is presented in geographic projection (lat/ long projection) with 720 columns and 360 rows. A general problem of this data set is that it is only available until 2006 and it works with coarse land use/cover classes. An example of monthly AVHRR - LAI (June 2000) for Central Asia (Kazakhstan) with $16 \mathrm{~km}$ spatial resolution is shown in Figure 5. All global AVHRR LAI data sets can be downloaded at http://cliveg.bu.edu/modismisr/index.html.

\subsubsection{LAI Derived from the SPOT VEGETATION Instrument.} The LAI product derived from VEGETATION (medium resolution sensor aboard SPOT4 and SPOT5 satellites) is

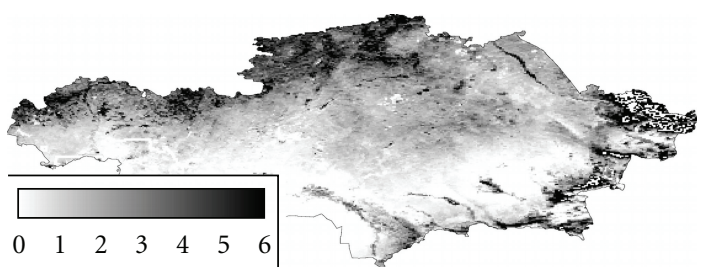

Figure 5: Mean peak season AVHRR-LAI (June 2000) over Kazakhstan.

based on a method, defined by the CSE team of INRA Avignon (http://w3.avignon.inra.fr/valeri/). In version 3 of the CYCLOPES algorithms LAI, vegetation fractional cover (Fcover) and fAPAR are assessed by inverting the radiative transfer model SAIL using neural networks [39].

The LAI is calculated as function of vegetation fractional cover, the leaf projection factor, and the clumping index, whereas the second and third variables represent biomespecific constants. This method is applied to VEGETATION data. More details on the CYCLOPES algorithms can be found in [40]. The LAI, Fcover, and fAPAR (1999-2003) are packed in a product called "Biophysical". They are provided in tiles of $10^{\circ} \times 10^{\circ}$ covering the whole globe in plate-carrée projection. The CYCLOPES LAI takes an active part inside a validation process of existing global LAI products, coordinated by SFC/NASA in collaboration with POSTEL (Pôle de Observation des Surfaces continentales par Telédédection) and other product providers (as discussed in Garrigues et al. [7]).

The validation consists of

(i) the intercomparison with LAI products derived in the frame of other projects (MODIS, GLOBCARBON, ECOCLIMAP, CCRS) [7],

(ii) the comparison with insitu measurements collected over the experimental site of ground networks and up-scaling approaches using high resolution satellite images (full list at http://lpvs.gsfc.nasa.gov/lai_ intercomp.php).

First results, presented at the Global Land Monitoring Workshop held in Missoula (2006), showed that the CYCLOPES LAI in comparison displays the best spatiotemporal consistency [7]. Further, it fits best the ground measurements, in spite of a low LAI level over the dense forests.

The CYCLOPES LAI products (hdf-format) can be downloaded from http://postel.mediasfrance.org/sommaire .php3?langue $=$ English .

Further studies after the Missoula event 2006 concentrated on the development of LAI integration algorithms that incorporate existing multiple LAI products [41]. Wang and Liang [42] presented a new data integration method based on empirical orthogonal function (EOF) analysis. The EOF integration algorithm can be used on both fine and coarse spatial resolution. Comparisons with high-spatial-resolution LAI reference maps from 12 sites over North America showed that the proposed method can improve LAI product accuracy 
[42]. The improvement of this method was more significant for MODIS as for CYCLOPES products.

3.1.3. LAI from the GEOLAND Project. GEOLAND was a European FP6 Integrated Project aiming at providing to GMES (Global Monitoring of Environment and Security, EU) services in the "water and carbon," "crop production for food safety," and "land cover change" areas the biogeophysical products that they need. POSTEL was leader of the GEOLAND Biogeophysical Parameter Core Service (CSP) and distributes to users several CSP products: leaf area index, fraction of absorbed PAR, fraction of vegetation cover, surface reflectances, burnt areas, surface albedo, downwelling shortwave and longwave radiation fluxes, surface temperature, precipitation, soil moisture, evapotranspiration, and water bodies. The action is going on in the framework of FP7 Collaborative Project GEOLAND-2 which started in September 2008.

GEOLAND aims to build up a European capacity for GMES. Two core services have been established to serve the GEOLAND observatories, providing them with basic geoinformation products. The Core Service "biogeophysical" Parameter (CSP) uses the CYCLOPES LAI derived from VEGETATION data to elaborate customized product according to the Observatory Natural Carbon (ONC) requirements. ONC needs $0.5^{\circ} \times 0.5^{\circ}$ tiled averages (mean and standard deviation values) maps of LAI for 8 vegetation classes ("conifer evergreen forest," "deciduous forest," "broadleaf evergreen forest," "grassland C3," "grassland C4," "crops C3," "crops C4"). LAI is also provided to the Observatory Food Security and Crop Monitoring (OFM) for crop yield studies. For ONC needs, the average and the standard deviation values are calculated over boxes of $0.5^{\circ}$ for 8 vegetation types. As the CYCLOPES LAI is actually an effective LAI, a clumping index during the customisation is applied. This coverdependent empirical clumping index is derived using the approach suggested by [43]. The number of valid pixel in the boxes of $0.5^{\circ}$ for each class is also provided as a data layer.

The customized 10-day LAI products currently available are derived from version 1 of CYCLOPES products, for years 2002 and 2003. They are provided with an algorithmic description and a readme file. The GEOLAND LAI products for 2002 and 2003 (presented in raw binary format) can be downloaded from http://postel.mediasfrance.org/sommaire .php3?langue=English.

3.1.4. LAI from MODIS. The Boston University, Department of Geography, delivers global LAI products based on Terra/ Aqua-MODIS Fraction of Absorbed Photosynthetic Active Radiation (fPAR) products (MOD15A2). For a detailed description of MOD15A2 product, see Knyazikhin et al. [11] and Myneni et al. $[8,37]$. The latest MOD15A2 product (Collection 5) replaced the old 6-biome LAI/FPAR biome map with new 8-biome map. Broadleaf and needle leaf forests classes were splitted into deciduous and evergreen subclasses. Algorithm refinements were carried out to improve quality of LAI/FPAR retrievals, and consistency with field measurements over all biomes, but with major focus on woody vegetation.
Each biome represents a pattern of the shape of an individual tree (leaf normal orientation, stem-trunk-branch area fractions, leaf and crown size) and the entire canopy (trunk distribution, topography), as well as patterns of spectral reflectance and transmittance of vegetation elements. Moreover, the soil type and understorey type are considered as biome characteristics, which can alter continuously within given biome specific thresholds. The distribution of leaves is described by the leaf area density distribution function which also depends on some continuous parameters. The eight biomes are grasses and cereal crops (biome 1), shrub (biome 2), broad leaf crops (biome 3), savanna (biome 4), evergreen broad leaf forest (biome 5), deciduous broad leaf forest (biome 6), evergreen needleleaf forest (biome 7), and deciduous needleleaf forest (biome 8). The following land cover classes are excluded from the calculation: urban, builtup class, permanent wetlands, marshes, perennial snow, ice, tundra, barren, desert, or very sparsely vegetated areas, water (ocean or in land water).

The MODIS LAI products are available at https://lpdaac .usgs.gov/get_data/data_pool.

The global LAI products are available as monthly composites with different spatial resolution $(1 \mathrm{~km}, 4 \mathrm{~km}$, and $0.25^{\circ}$ ) for the period from February 2000 till present. Global 8 -days composites are available with a spatial resolution of $0.25^{\circ}$ starting at Julian day 57 of the year 2000 .

3.1.5. Suitability of the Available Global LAI Products for Applications in Central Asia. A short summary of the available global LAI products is listed in Table 3. For global applications various consistent time series of LAI exist with $1 \mathrm{~km} \times 1 \mathrm{~km}$ spatial resolution. Independent assessment of product quality is a critical step to the success of a global LAI product usage. The satellite-modelled LAI products evidently simplify reality and require extensive validation, which is based on ground truth information from a possible greatest number of sites representing all the biomes included in the model. For instance, the reports about activities of MODIS LAI validation in different earth regions and various biomes climb in recent literature (e.g., $[7,19,30,44])$. Results from validation studies around the world are being successfully used to adjust and refine MODIS LAI [45]. However, all the validation activities have been mostly focused on certain biomes (predominantly forest and cropland) in test sites located in the western hemisphere, while validation studies from the eastern hemisphere have been very scarce. Similar problem also concerns other global LAI products. With respect to the grassland biome, MODIS LAI products have been checked against ground-based data only in a semiarid region of Africa $[19,30,46]$.

The Eurasian temperate grassland, representing the world largest grassland biome, with its east-west extension of more than $6000 \mathrm{~km}$ and a north-south extension of about $1490 \mathrm{~km}$, has been out of scope of extensive validation efforts. The existing global LAI products have not been checked in any region or biome of Central Asia yet. In our current knowledge, there are no published studies on validation of any global LAI products in Central Asia. Within this scope, an ongoing research work on validation of the existing global 
TABLE 3: Available LAI products with global coverage.

\begin{tabular}{|c|c|c|c|c|c|}
\hline Sensor & Coverage & Project/product & Spatial resolution & Temporal resolution & Temporal availability \\
\hline $\begin{array}{l}\text { AVHRR } \\
\text { NOAA-9 } \\
\text { and NOAA-11 }\end{array}$ & Global & ISLSCP & $1^{\circ}(\times \mathrm{km})$ & Monthly & $1987-1988$ \\
\hline AVHRR & Global & Boston University & $0.5^{\circ}(\times \mathrm{km})$ & Monthly & $07 / 1981$ to $05 / 2001$ \\
\hline AVHRR & Global & Boston University & $16 \mathrm{~km}$ & Monthly & $07 / 1981$ to $05 / 2001$ \\
\hline AVHRR & Global & Ecoclimap & $1 \mathrm{~km}$ & Monthly & $\begin{array}{c}1992 \text { to } 1993 \\
1997\end{array}$ \\
\hline VEGETATION & Global & Cyclopes & $1 \mathrm{~km}$ & 10 days & 1999 to 2003 \\
\hline VEGETATION & Global & Geoland & $0.5^{\circ}$ & 10 days & 2002 to 2003 \\
\hline $\begin{array}{l}\text { VEGETATION } \\
\text { ATSR }\end{array}$ & Global & Globcarbon & $1 \mathrm{~km} / 10 \mathrm{~km} / 0.25^{\circ} / 0.5^{\circ}$ & 10 days & 1998 to 2007 \\
\hline POLDER & Global & Polder-1 & $6 \mathrm{~km}$ & 10 days & 1996 to 1997 \\
\hline POLDER & Global & Polder-2 & $6 \mathrm{~km}$ & 10 days & 2003 \\
\hline $\begin{array}{l}\text { MODIS } \\
\text { TERRA/AQUA }\end{array}$ & Global & MOD15A2 & $1 \mathrm{~km}$ & Daily and 8 days & 2000 until present \\
\hline $\begin{array}{l}\text { MODIS } \\
\text { TERRA/AQUA combined }\end{array}$ & Global & MOD15A3 & $1 \mathrm{~km}$ & 4 days & July 2002 until present \\
\hline
\end{tabular}

NASA: national aeronautics and space administration.

AVHRR: advanced very high resolution radiometer.

ISLSCP: international land surface climatology project.

MODIS: moderate resolution imaging spectroradiometer.

POLDER: polarization and directionality of the earth's reflectance.

VEGETATION: vegetation sensor aboard spot 4 and spot5 satellites.

LAI products in a grassland region in Central Kazakhstan is of great importance. This work is being carried out at the Department of GIS and Remote Sensing (University of Göttingen, Germany) and uses extensive field measurements of LAI as reference data for validation of global LAI products. As first, the validation of MODIS LAI product has been finished by this research group and its results will be published. Results of the MODIS LAI validation showed that MOD15A2 overestimates the ground-based LAI by $10-15 \%$ during the growing season. This study also found great problems with MODIS LAI outside the growing season: LAI values of $0.1-0.15$ were maintained throughout the year, even during periods with air temperature below $0^{\circ} \mathrm{C}$. Similar results have been reported by [19] for a semidesert grassland in Africa.

Another strategy for validation of global LAI products is a comparison of different LAI products with each other. LAI products intercomparison enables to separate differences in LAI values caused by the satellite input data from differences caused by the used LAI algorithm [47, 48]. The intercomparison and validation of the existing global LAI products, coordinated by GSFC/NASA in collaboration with Postel and other product providers, revealed that, for the time period 1999 to 2003, it is recommended to use the CYCLOPESVEGETATION data (whole study, described in [7]). When LAI time-series with $1 \mathrm{~km} \times 1 \mathrm{~km}$ spatial resolution from 2000 to present are needed, the only source is MODIS with the MOD15A2 product. The time series of VEGETATION and MODIS differ in the temporal resolution (VEGETATION: 10 days; MODIS: 8 days). Therefore, a harmonization of both time series is needed.
With respect to the spatial dimension of the Central Asian grassland and its importance for global carbon cycle and climate change, the work on validation of the existing global LAI products should be strengthened.

\section{Available Local and Regional LAI Data Sets for Central Asia}

For local or regional applications with spatial resolutions of less than $1000 \mathrm{~m} \times 1000 \mathrm{~m}$, no global LAI dataset is available. All higher spatial resolution sensors with a swath width of a few kilometres to $200 \mathrm{~km}$ (Landsat ETM+) have a revisit time of 2 weeks or more. In order to produce LAI time series from these sensors, temporal interpolation is required. Therefore, the number of observations for one test site is limited by the number of cloud free over flights.

The use of biome-specific parameter values in algorithms of the global LAI products neglects the variability of the landscape within an individual biome. At the local to regional scale, the algorithm can be improved by incorporating perpixel information on the above-mentioned parameters into the modeling approach as shown in recent studies (e.g., [49, 50]). Unfortunately, there are only a few published studies from Central Asia or its regions presenting satellite-based LAI products produced at local and regional scale.

In the study by Propastin and Kappas [51], fine-resolution Landsat ETM+ imagery was combined with in situ measured data to map LAI over a 200-300 km large grassland region in Central Kazakhstan. The authors tested usability of different vegetation indices and transfer techniques (statistical regression, geostatistics) for predicting LAI from Landsat 
ETM+ data. They also examined consistency between contact and noncontact LAI measurement methods in field and found good correspondence between LAI values calculated from grass harvesting technique (contact method) with LAI values produced from hemispherical photography (noncontact method).

Propastin and Kappas [26] developed a $1 \mathrm{~km}$ spatial resolution LAI data set for the semidesert and steppe biomes in Kazakhstan using SPOT-VGT-based NDVI and in situ measurements. Their empirical approach consisted of two steps. In the first step, they used a simple statistical regression between field-measured LAI values and a fine-resolution satellite data (Landsat ETM+) for mapping LAI over the area of the field measurements. In the second step, a regression model between the Landsat-based LAI map, which had previously been degraded to the spatial resolution of $1 \mathrm{~km}$, and SPOT-VGT NDVI was produced at the per-pixel basis. After that, LAI was mapped over the whole area of semidesert and steppe vegetation in Kazakhstan. The produced LAI data set was then employed in modelling net ecosystem exchange in Central Kazakhstan (see Propastin and Kappas [52]).

\section{Designing Improved LAI Data Sets for Central Asia (Kazakhstan)}

Apart from the local and regional LAI data sets described in Section 4, a work on a development and validation of new coarse-resolution LAI products for the grassland of Central Asia and Kazakhstan is underway. The first product is based on the $8 \mathrm{~km}$ spatial resolution AVHRR data (Goettingen GIS and Remote Sensing GGRS-data set, see Propastin et al. [53]) while the second product employes the $1 \mathrm{~km}$ spatial resolution SPOT-VEGETATION data (Propastin and Kappas [26]). Both products use a satellite-based LAI algorithm developed in the Department for GIS and RS at GeorgAugust University of Göttingen, Germany [50, 54]. This algorithm uses a three-dimensional physical radiative transfer model which establishes relationship between LAI, vegetation fractional cover and given patterns of surface reflectance, view-illumination conditions and optical properties of vegetation. The model incorporates a number of site/regionspecific parameters, including the vegetation architecture variables such as leaf angle distribution, clumping index, and light extinction coefficient. For the application of the model to Kazakhstan, the vegetation architecture variables were computed at the local (pixel) level based on extensive field surveys of the biophysical properties of vegetation in representative grassland areas of Kazakhstan. Influence of viewillumination conditions on optical properties of vegetation was simulated by a view angle geometry model incorporating the solar zenith angle and the sensor viewing angle.

After finishing the ongoing work, the new LAI products, covering spatially the whole area of grassland in Central Asia (Kazakhstan) and temporally the period 1982-2010 (for the AVHRR-based product) and 1998-2010 (for the SPOTVEGETATION-based product), respectively, will be freely available to the public use on the Google Earth Engine Initiative.

\section{Conclusions}

Remote sensing techniques have many advantages in LAI estimation over traditional field measurement methods and provide the potential to estimate LAI at different scales. This paper reviewed LAI products available for environmental and ecological modelling in the formerly Soviet Central Asia (especially Kazakhstan) with a focus on grassland biome and outlined issues of their application. The following main conclusions can be made from the review.

(1) The studied region is characterized by its enormous role in the global carbon cycle and global change. However, ecological modelling studies in the formerly Soviet Central Asia cannot be supplied by region-specific LAI data sets adequately.

(2) The use of existing global LAI products is limited by their spatial resolution (1000 $\mathrm{m}$ and coarser) and unknown suitability for this region. No one of the global LAI products has been compared with groundbased data from the region. Validation of global LAI products just begins in grassland of Kazakhstan. First results of this validation work revealed moderate consistency of MODIS LAI product with ground-based measurements at the peak of the growing season and high inconsistency outside the growing season.

(3) There are only a few region-specific existing LAI products, which base on ground LAI from this region. These products have successfully been used for ecological modelling in the grasslands of Central Kazakhstan.

With these conclusions in background, future research may focus on the amplification of validation of the existing global LAI products, and the development of new region-specific LAI products. By developing new LAI products for this region, new generation sensors and future advanced sensor developments that have more spectral channels in the VIS and NIR domain may be used. With the use of the newer sensors and in due consideration of different observation geometries during consecutive overpasses it is possible to implement different techniques to invert models tracing the radiation transfer in vegetation.

\section{References}

[1] I. Jonckheere, S. Fleck, K. Nackaerts et al., "Review of methods for in situ leaf area index determination Part I. Theories, sensors and hemispherical photography," Agricultural and Forest Meteorology, vol. 121, no. 1-2, pp. 19-35, 2004.

[2] S. W. Running, P. E. Thornton, and R. Nemani, "Global terrestrial gross and net primary productivity from the earth observing system," in Methods in Ecosystem Science, O. E. Sala, R. B. Jackson, H. A. Mooney, and R. W. Howarth, Eds., pp. 44-57, Springer, New York, NY, USA, 2000.

[3] J. M. Chen, J. Liu, J. Cihlar, and M. L. Goulden, "Daily canopy photosynthesis model through temporal and spatial scaling for remote sensing applications," Ecological Modelling, vol. 124, no. 2-3, pp. 9-119, 1999. 
[4] R. Lal, "Carbon sequestration in soils of Central Asia," Land Degradation and Development, vol. 15, no. 6, pp. 563-572, 2004.

[5] G. M. Henebry, "Global change: carbon in idle croplands," Nature, vol. 457, no. 7233, pp. 1089-1090, 2009.

[6] J. S. Amthor and D. D. Baldocchi, "Terrestrial higher plant respiration and net primary production," in Terrestrial Global Productivity, pp. 33-59, Academic Press, 2001.

[7] S. Garrigues, R. Lacaze, F. Baret et al., "Validation and intercomparison of global Leaf Area Index products derived from remote sensing data," Journal of Geophysical Research G, vol. 113, no. 2, Article ID G02028, 2008.

[8] R. B. Myneni, "Estimation of global leaf area index and absorbed par using radiative transfer models," IEEE Transactions on Geoscience and Remote Sensing, vol. 35, no. 6, pp. 13801393, 1997.

[9] F. Deng, J. M. Chen, S. Plummer, M. Chen, and J. Pisek, “Algorithm for global leaf area index retrieval using satellite imagery," IEEE Transactions on Geoscience and Remote Sensing, vol. 44, no. 8, pp. 2219-2228, 2006.

[10] M. Weiss and F. Baret, "Evaluation of canopy biophysical variable retrieval performances from the accumulation of large swath satellite data," Remote Sensing of Environment, vol. 70, no. 3, pp. 293-306, 1999.

[11] Y. Knyazikhin, J. V. Martonchik, D. J. Diner et al., "Estimation of vegetation canopy leaf area index and fraction of absorbed photosynthetically active radiation from atmosphere-corrected MISR data," Journal of Geophysical Research D, vol. 103, no. 24, pp. 32239-32256, 1998.

[12] C. Bacour, F. Baret, D. Béal, M. Weiss, and K. Pavageau, "Neural network estimation of LAI, fAPAR, fCover and LAI $\times$ Cab, from top of canopy MERIS reflectance data: principles and validation," Remote Sensing of Environment, vol. 105, no. 4, pp. 313-325, 2006.

[13] P. J. Sellers, S. O. Los, C. J. Tucker et al., "A revised land surface parameterization (SiB2) for atmospheric GCMs. Part II: the generation of global fields of terrestrial biophysical parameters from satellite data," Journal of Climate, vol. 9, no. 4, pp. 706737, 1996.

[14] J. M. Chen, F. Deng, and M. Chen, "Locally adjusted cubicspline capping for reconstructing seasonal trajectories of a satellite-derived surface parameter," IEEE Transactions on Geoscience and Remote Sensing, vol. 44, no. 8, pp. 2230-2237, 2006.

[15] F. Gao, J. T. Morisette, R. E. Wolfe et al., "An algorithm to produce temporally and spatially continuous MODIS-LAI time series," IEEE Geoscience and Remote Sensing Letters, vol. 5, no. 1, pp. 60-64, 2008.

[16] B. Tan, J. T. Morisette, R. E. Wolfe et al., "Vegetation phenology metrics derived from temporally smoothed and gap-filled modis data," in Proceedings of the IEEE International Geoscience and Remote Sensing Symposium (IGARSS '08), vol. 3, pp. III593-III596, July 2008.

[17] P. A. Propastin, M. Kappas, and N. R. Muratova, "Interannual changes in vegetation activities and their relationship to temperature and precipitation in Central Asia from 1982 to 2003," Journal of Environmental Informatics, vol. 12, no. 2, pp. 75-87, 2008.

[18] M. A. Friedl, F. W. Davis, J. Michaelsen, and M. A. Moritz, "Scaling and uncertainty in the relationship between the NDVI and land surface biophysical variables: an analysis using a scene simulation model and data from FIFE," Remote Sensing of Environment, vol. 54, no. 3, pp. 233-246, 1995.
[19] R. Fensholt, I. Sandholt, and M. S. Rasmussen, "Evaluation of MODIS LAI, fAPAR and the relation between FAPAR and NDVI in a semi-arid environment using in situ measurements," Remote Sensing of Environment, vol. 91, no. 3-4, pp. 490-507, 2004.

[20] S. Jacquemoud, F. Baret, B. Andrieu, F. M. Danson, and K. Jaggard, "Extraction of vegetation biophysical parameters by inversion of the PROSPECT+SAIL models on sugar beet canopy reflectance data. Application to TM and AVIRIS sensors," Remote Sensing of Environment, vol. 52, no. 3, pp. 163-172, 1995.

[21] P. Bicheron and M. Leroy, "A method of biophysical parameter retrieval at global scale by inversion of a vegetation reflectance model," Remote Sensing of Environment, vol. 67, no. 3, pp. 251266, 1999.

[22] S. Jacquemoud and S. L. Ustin, "Leaf optical properties: a state of the art," in Proceedings of the 8th International Symposium Physical Measurements \& Signatures in Remote Sensing, pp. 223-232, Aussois, France, 2001.

[23] M. Weiss, F. Baret, G. J. Smith, I. Jonckheere, and P. Coppin, "Review of methods for in situ leaf area index (LAI) determination Part II. Estimation of LAI, errors and sampling," Agricultural and Forest Meteorology, vol. 121, no. 1-2, pp. 3753, 2004.

[24] P. A. Propastin, "Spatial non-stationarity and scale-dependency of prediction accuracy in the remote estimation of LAI over a tropical rainforest in Sulawesi, Indonesia," Remote Sensing of Environment, vol. 113, no. 10, pp. 2234-2242, 2009.

[25] J. M. O. Scurlock, G. P. Asner, and S. T. Gower, "Worldwide historical estimates of leaf area index, 1932-2000,” ORNL Technical Memorandum ORNL/TM-2001/268, Oak ridge National Laboratory, Oak Ridge, Tenn, USA, 2001.

[26] P. Propastin and M. Kappas, "Mapping Leaf Area Index over semi-desert and steppe biomes in Kazakhstan using satellite imagery and ground measurements," EARSEL eProceedings, vol. 8, no. 1, pp. 75-92, 2009.

[27] R. H. Whittaker and W. A. Niering, "Vegetation of the Santa Catalina Mountains, Arizona: biomass, production, and diversity along the elevation gradient," Ecology, vol. 55, pp. 771790, 1975.

[28] G. P. Asner, J. M. O. Scurlock, and J. A. Hicke, "Global synthesis of leaf area index observations: implications for ecological and remote sensing studies," Global Ecology and Biogeography, vol. 12, no. 3, pp. 191-205, 2003.

[29] G. P. Asner, C. A. Wessman, C. A. Bateson, and J. L. Privette, "Impact of tissue, canopy, and landscape factors on the hyperspectral reflectance variability of arid ecosystems," Remote Sensing of Environment, vol. 74, no. 1, pp. 69-84, 2000.

[30] M. J. Hill, U. Senarath, A. Lee et al., "Assessment of the MODIS LAI product for Australian ecosystems," Remote Sensing of Environment, vol. 101, no. 4, pp. 495-518, 2006.

[31] J. M. Chen and J. Cihlar, "Retrieving leaf area index of boreal conifer forests using landsat TM images," Remote Sensing of Environment, vol. 55, no. 2, pp. 153-162, 1996.

[32] J. D. White, S. W. Running, R. Nemani, R. E. Keane, and K. C. Ryan, "Measurement and remote sensing of LAI in rocky mountain montane ecosystems," Canadian Journal of Forest Research, vol. 27, no. 11, pp. 1714-1727, 1997.

[33] W. B. Cohen, T. K. Maiersperger, S. T. Gower, and D. P. Turner, "An improved strategy for regression of biophysical variables and Landsat ETM+ data," Remote Sensing of Environment, vol. 84, no. 4, pp. 561-571, 2003.

[34] M. Berterretche, A. T. Hudak, W. B. Cohen, T. K. Maiersperger, S. T. Gower, and J. Dungan, "Comparison of regression and 
geostatistical methods for mapping Leaf Area Index (LAI) with Landsat ETM+ data over a boreal forest," Remote Sensing of Environment, vol. 96, no. 1, pp. 49-61, 2005.

[35] L. Brown, J. M. Chen, S. G. Leblanc, and J. Cihlar, "A shortwave infrared modification to the simple ratio for LAI retrieval in boreal forests: an image and model analysis," Remote Sensing of Environment, vol. 71, no. 1, pp. 16-25, 2000.

[36] J. E. Pinzon, M. E. Brown, and C. J. Tucker, "Global Inventory Modelling and Mapping Studies (GIMMS) AVHRR 8-km Normalized Difference Vegetation Index (NDVI) data set," Product Guide, 2004, http://landcover.org/library/guide/ GIMMSdocumentation_NDVIg_8km_rev4.pdf.

[37] R. B. Myneni, S. Hoffman, Y. Knyazikhin et al., "Global products of vegetation leaf area and fraction absorbed PAR from year one of MODIS data," Remote Sensing of Environment, vol. 83, no. 1-2, pp. 214-231, 2002.

[38] W. Buermann, J. Dong, X. Zeng, R. B. Myneni, and R. E. Dickinson, "Evaluation of the utility of satellite-based vegetation leaf area index data for climate simulations," Journal of Climate, vol. 14, no. 17, pp. 3536-3550, 2001.

[39] W. Verhoef, "Light scattering by leaf layers with application to canopy reflectance modeling: the SAIL model," Remote Sensing of Environment, vol. 16, no. 2, pp. 125-141, 1984.

[40] F. Baret, O. Hagolle, B. Geiger et al., "LAI, fAPAR and fCover CYCLOPES global products derived from VEGETATION. Part 1: principles of the algorithm," Remote Sensing of Environment, vol. 110, no. 3, pp. 275-286, 2007.

[41] M. Weiss, F. Baret, S. Garrigues, and R. Lacaze, "LAI and fAPAR CYCLOPES global products derived from VEGETATION. Part 2: validation and comparison with MODIS collection 4 products," Remote Sensing of Environment, vol. 110, no. 3, pp. 317-331, 2007.

[42] D. Wang and S. Liang, "Integrating MODIS and CYCLOPES leaf area index products using empirical orthogonal functions," IEEE Transactions on Geoscience and Remote Sensing, vol. 49, no. 5, pp. 1513-1519, 2011.

[43] J. L. Roujean and R. Lacaze, "Global mapping of vegetation parameters from POLDER multiangular measurements for studies of surface-atmosphere interactions: a pragmatic method and its validation," Journal of Geophysical Research D, vol. 107, no. 12, pp. 6-14, 2002.

[44] Y. Tian, Y. Wang, Y. Zhang, Y. Knyazikhin, J. Bogaert, and R. B. Myneni, "Radiative transfer based scaling of LAI retrievals from reflectance data of different resolutions," Remote Sensing of Environment, vol. 84, no. 1, pp. 143-159, 2003.

[45] W. Yang, B. Tan, D. Huang et al., "MODIS leaf area index products: from validation to algorithm improvement," IEEE Transactions on Geoscience and Remote Sensing, vol. 44, no. 7, pp. 1885-1896, 2006.

[46] J. L. Privette, R. B. Myneni, Y. Knyazikhin et al., "Early spatial and temporal validation of MODIS LAI product in the southern Africa Kalahari," Remote Sensing of Environment, vol. 83, no. 1-2, pp. 232-243, 2002.

[47] J. Pisek and J. M. Chen, "Comparison and validation of MODIS and VEGETATION global LAI products over four BigFoot sites in North America," Remote Sensing of Environment, vol. 109, no. 1, pp. 81-94, 2007.

[48] M. Weiss, F. Baret, S. Garrigues, and R. Lacaze, "LAI and fAPAR CYCLOPES global products derived from VEGETATION. Part 2: validation and comparison with MODIS collection 4 products," Remote Sensing of Environment, vol. 110, no. 3, pp. 317-331, 2007.

[49] M. Sprintsin, A. Karnieli, P. Berliner, E. Rotenberg, D. Yakir, and S. Cohen, "The effect of spatial resolution on the accuracy of leaf area index estimation for a forest planted in the desert transition zone," Remote Sensing of Environment, vol. 109, no. 4, pp. 416-428, 2007.

[50] P. Propastin and S. Erasmi, "A physically based approach to model LAI from MODIS 250m data in a tropical region," International Journal of Applied Earth Observation and Geoinformation, vol. 12, no. 1, pp. 47-59, 2010.

[51] P. Propastin and M. Kappas, "Mapping Leaf Area Index in a semi-arid environment of Kazakshtan using fine-resolution satellite data and in situ measurements," GIScience \& Remote Sensing, vol. 46, no. 2, pp. 212-231, 2009.

[52] P. Propastin and M. Kappas, "Modeling net ecosystem exchange for grassland in Central Kazakhstan by combining remote sensing and field data," Remote Sensing, vol. 1, no. 3, pp. 159-183, 2009.

[53] P. Propastin, M. Kappas, S. Herrmann, and C. J. Tucker, "Modified light use efficiency model for assessment of carbon sequestration in grasslands of Kazakhstan: combining ground biomass data and remote sensing," International Journal of Remote Sensing, vol. 33, no. 5, pp. 1465-1487, 2012.

[54] P. Propastin and M. Kappas, "Retrieval of coarse-resolution leaf area index over the Republic of Kazakhstan using NOAA AVHRR satellite data and ground measurements," Remote Sensing, vol. 4, no. 1, pp. 220-246, 2011. 

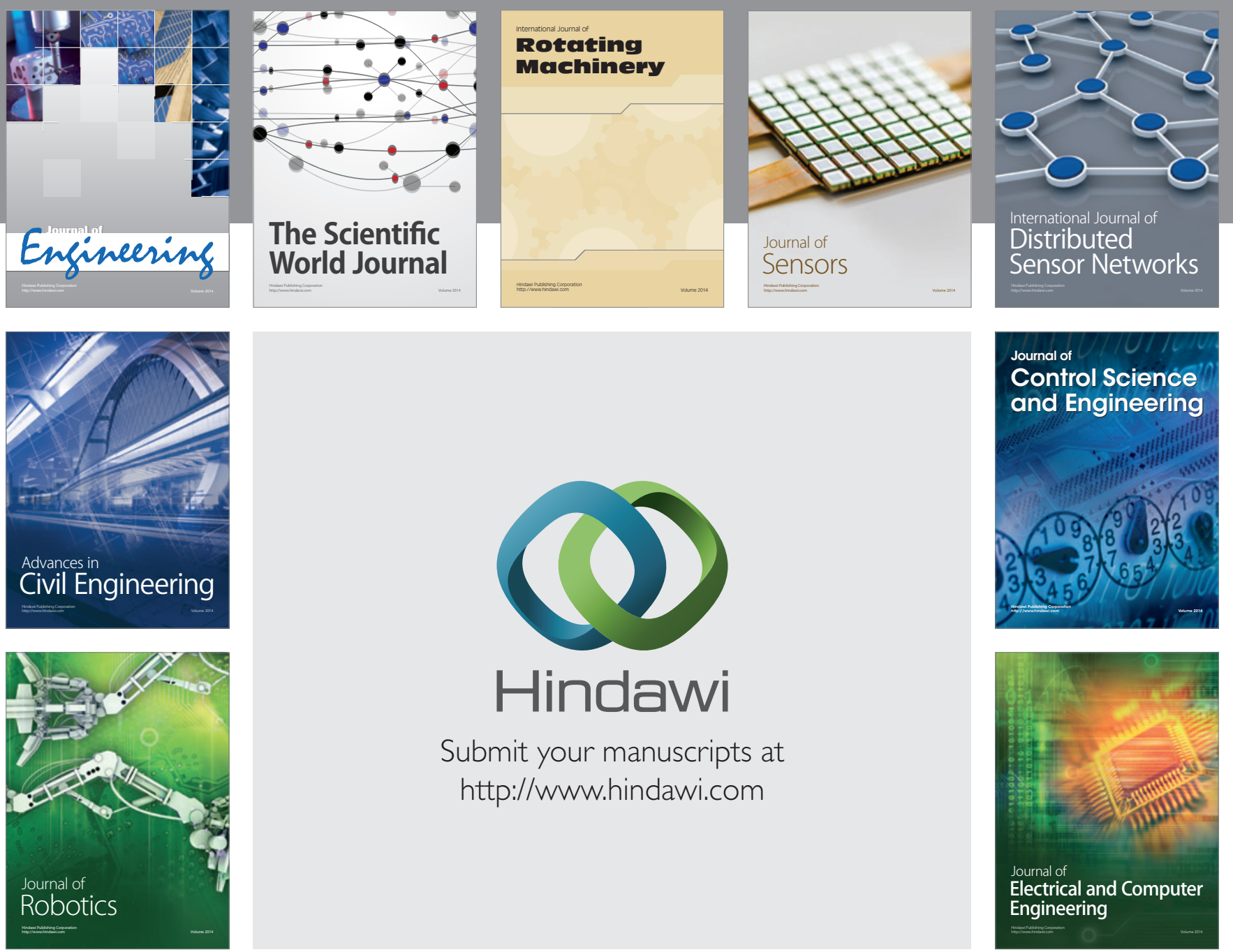

Submit your manuscripts at

http://www.hindawi.com
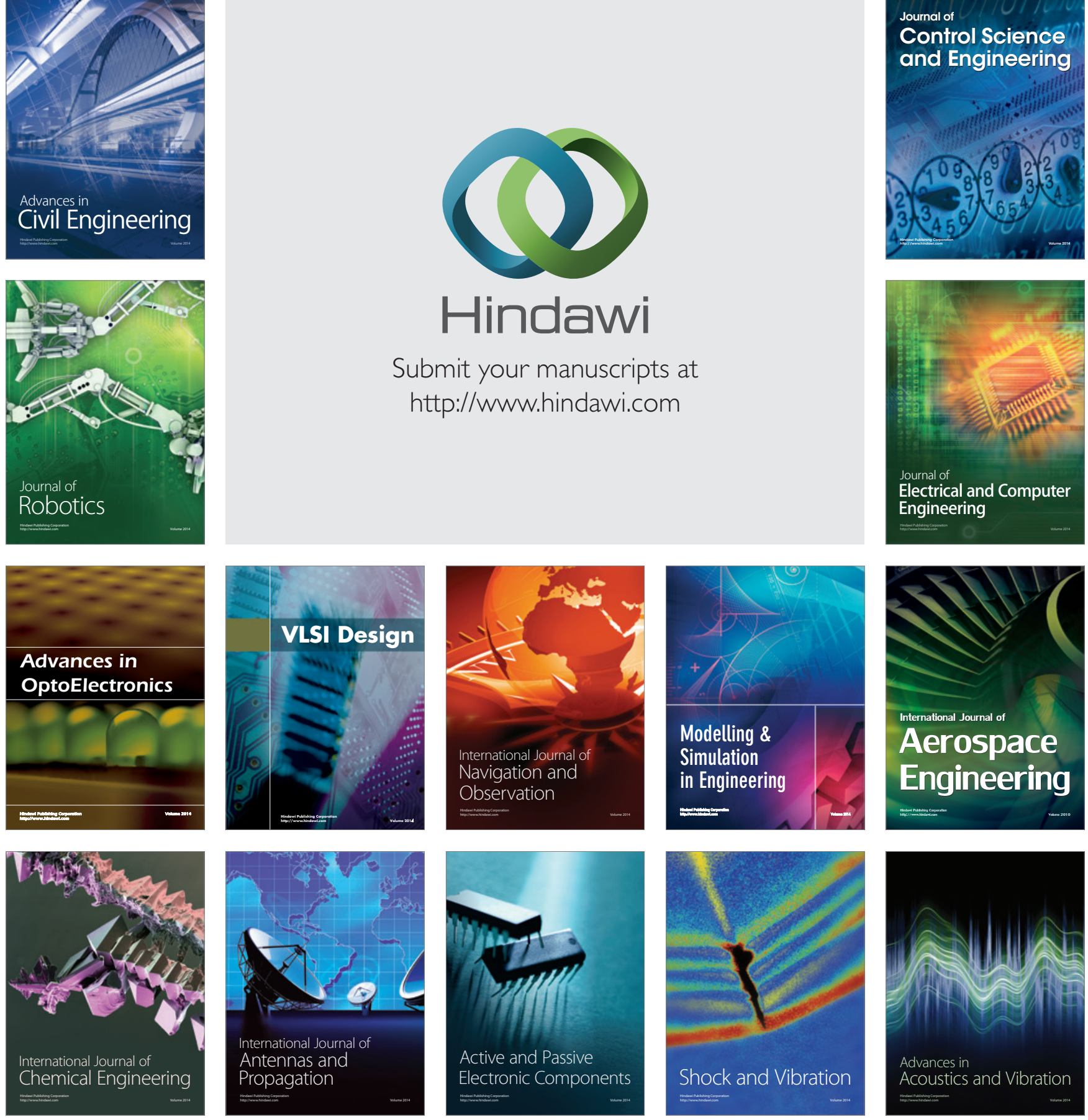